\title{
Nikel Alaşımlarının Farklı Soğutma/Yağlama Koşulları Altında Talaşı İmalatının Kesme Kuvvetlerine Etkisi: Bir Derleme Çalışması
}

\author{
The Effect of Machining of Nickel Alloys on Cutting Force under Different Cooling/ Lubrication \\ Conditions: A Review
}

\author{
Muhammed TAŞBAŞI ${ }^{1}$ (D), Mustafa AY ${ }^{\mathbf{1}}$ \\ ${ }^{1}$ Marmara Üniversitesi Teknoloji Fakültesi Makine Mühendisliği Bölümü,34722, ISTABUL/TÜRKIYE
}

$\ddot{O} \mathbf{z}$

Nikel alaşımları, yüksek sıcaklıklarda mekanik özelliklerini koruyabilme ve korozyona karşı yüksek direnç özellikleri nedeniyle, yüksek sıcaklık ve korozyona maruz kalan havacılık ve uzay, nükleer enerji, petrokimya endüstrisi gibi güvenlik ve sürdürülebilirliğin hayati önem taşıdığı kritik endüstri uygulamalarında önemli yer tutar. Nikel alaşımlarının gelişmiş özellikleri, bu alaşımların talaşlı imalatı sırasında yüksek kesme kuvvetleri, kesme bölgesi sıcaklığı ve sonrasında birtakım problemlerin oluşmasına neden olmaktadır. Birbirleriyle oldukça ilişkili bu problemlere çözüm olarak bazı yaklaşımlar geliştirilmiştir. Bu çalışma; literatürdeki, nikel alaşımlarının farklı soğutma/yağlama koşullarında, farklı talaşlı imalat yöntemleriyle işlenmesi ile ilgili çalışmaların talaşlı imalat sırasında oluşan kesme kuvvetleri üzerindeki etkilerinin bir incelemesini sunar. Yapılan deneysel çalışmaların çoğunda, karakteristiklerine göre kuru, konvansiyonel, Minimum miktarda yağlama (MQL) ve kriyojenik koşullarda işleme metodları uygulanmıştır. Ancak bu metodların yanısıra, etkin bir uygulama için kesme parametreleri, takım kaplaması, nozul konumları gibi birçok unsurun göz önüne alınması gerekmektedir. Çalışmalar, kesme kuvvetlerini azaltma konusunda kriyojenik metodun yüksek hızlarda diğer metodların çoğuna göre oldukça etkili olduğunu göstermiştir. Ancak kriyojenik metod, tek başına yeterli olmamakta ve alternatif olarak Kriyojenik ve MQL metodlarının birleşimi olan hibrid KriyoMQL soğutma/ yağlama metodunun kullanımı yaygınlaşmaya başlamıştır. Literatürdeki araştırmalarında ışı̆̆ına bu metodun nikel alaşımlarının talaşlı imalatında kesme kuvvetlerinin ve kesme bölgesi sıcaklıklarının azaltılmasında gelecekte etkin bir metod olabileceği sonucuna varılmıştır.

Anahtar Kelimeler: KriyoMQL, MQL, Nikel Alaşımları, Kesme Kuvveti, Talaşlı İmalat

\begin{abstract}
Nickel alloys have high resistance to corrosion at high temperatures and have high resistance to corrosion, and they play an important role in critical industry applications where safety and sustainability is very important, such as aerospace, petrochemical and nuclear power industries which working under high corrosion and heat effect. These advanced properties of nickel alloys result in high cutting forces, cutting zone temperature and some surface integrity problems during and after machining of these alloys. Some approaches have been developed to solve these problems that are highly related to each other. This study provides a review of studies which focus on the effect of the processing of nickel alloys under different cooling / lubrication conditions with different machining methods on cutting forces during machining. In most of the experimental studies, dry, conventional liquids, Minimum quantity lubrication (MQL) and machining methods under cryogenic conditions were applied. A number of complex elements, such as cutting parameters, tool coating material, nozzle positions, must be considered for an effective application. Experimental studies have shown that the cryogenic cooling method is highly more effective than most of the other methods in reducing cutting forces. However, the cryogenic cooling method alone is not sufficient , alternatively, the use of a hybrid CryoMQL cooling / lubrication method, which is a combination of cryogenic cooling and MQL methods, has become widespread. As a result, The CryoMQL is concluded that nickel alloys can be an effective method in reducing cutting forces and cutting zone temperatures in machining.
\end{abstract}

Keywords; CryoMQL, MQL, Nickel Alloys, Cutting Force, Machining 


\section{I.GIRIŞ}

Nikel, $1453^{\circ} \mathrm{C}$ gibi oldukça yüksek erime sıcaklığına sahip, sahip korozyona dayanıklı ve yüzey merkezli kübik (YMK) kristal yapısı sayesinde iyi derecede süneklik seviyesine sahip bir metaldir. Nikel, diğer metalik elementlerle kolayca alaşım oluşturabilecek kabiliyette bir metaldir[1]. Nikel, diğer ana alaşım metalleri olan krom, demir ve kobalt yanında çok sayıda elementle belirli oranlarda alaşımlanarak süper alaşım adı verilen, oldukça yüksek sıcaklık ve korozyon direncine sahip alaşımları meydana getirebilir[2]. Nikel bazlı süper alaşımlar bu özellikleri nedeniyle yüksek sıcaklık ve korozyon direnci gerektiren havacılık ve uzay, petrokimya, enerji makineleri ve güç sistemleri endüstrileri uygulamalarında türbin diskleri, kanatçıklar, borular, bağlantı ekipmanları gibi yüksek sıcaklık ve korozyona maruz kalabilecek parçaların üretiminde sıkça kullanılmaktadır[3-7,23]. Nikel esaslı süper alaşımlar, sahip oldukları yüksek düzeydeki mekanik özellikleri, yüksek sıcaklıklarda mekanik özelliklerini koruyabilme kabiliyeti ve malzemenin zayıf termal iletkenlik kapasitesinin etkisiyle, talaşlı imalat süreçlerinde işlenebilirlik problemlerinin ortaya çıkmasına neden olmaktadırlar. Talaşlı imalat operasyonu sırasında ortaya çıkan yüksek basınç ve sıcaklıklar, talaşlı imalat sürecini zorlaştııırken ani soğuma durumları gibi durumlarda malzeme yapısında çarpılma olarak tabir edilen sertleşmelere neden olabilmektedir[7]. Nikel alaşımlarının yüksek sıcaklıklarda dahi gösterdiği yüksek mukavemet, kesme kuvvetlerinin korunmasına neden olurken, işleme esnasında malzeme sertleşmesi, malzeme yapısında bulunan aşındırıcı karbür partiküllerinin kesici takım hasarına neden olması, alaşımın işlenmesi sırasında oluşan yüksek sıcaklığın, kesici takım ve iş malzemesi arasında oluşturduğu kimyasal reaksiyonlardan kaynaklanan işleme hataları; nikel bazlı alaşımların işlenebilirliğini olumsuz etkileyen unsurlardır. Bu unsurlar kesme kuvvetlerinin artışına, takım ömrünün kısalmasına, işlenmiş parçalardaın ciddi anlamda yüzey ve yüzeyaltı hatalarına neden olurlar. Bu nedenle, talaşlı imalat sırasında iş parçasının yüzey bütünlüğünü sağlamak, kesme kuvvetlerini azaltmak ve takım ömrünü artırabilmek amacıyla; takım malzemesi seçimi, takım geometrisi, işleme yöntemi, kesme hızı, ilerleme, kesme derinliği gibi ana parametrelerin kontrol edilmesinin yanında soğutma/yağlama metodunun iyi seçilmesi gerekmektedir[8]. Kesme kuvvetleri, talaşlı imalat operasyonu sırasında birçok değişkenden etkilenen ölçütlerden biridir. Kesme kuvvetleri, talaş derinliği, ilerleme hızı, takım ve talaş geometrisi, iş malzemesi, kesme hızı, takım ve tezgah özellikleri, bağlama metodu, takım aşınmanın karakteristiği, titreşim, sıcaklık gibi unsurlardan etkilenebilmektedir. Bu nedenle takıma etki eden kesme kuvvetleri takım durumu hakkında önemli bir bilgi kaynağı oluşturur. Talaşlı imalat operasyonu sirasinda kesme kuvvetleri direkt olarak işleme sürecini etkilediğinden dolayı ciddi şekilde dikkate alınmalıdır. Kesme kuvvetlerinin; kesme sıcaklığı, takım aşınması, yüzey kalitesi ve daha birçok olgu ile oldukça yakın bir ilişkisi vardır. Verimli bir kesme işlemi için kesme kuvvetlerinin öngörülebilir olması gerekir[9-11,21].

\section{LITERATÜR ARAŞTIRMASI}

Literatürde nikel alaşımlarının, işlenebilirliğinin incelenmesi ve artırılması amacıyla yapılmış çok sayıda çalışma bulunmaktadır[8,11-13]. Yapılan bir literatür derleme araştırmasında nikel alaşımlarının, literatürde kullanılma sıklığı Şekil 1'de gösterilmiştir [13,14,24].

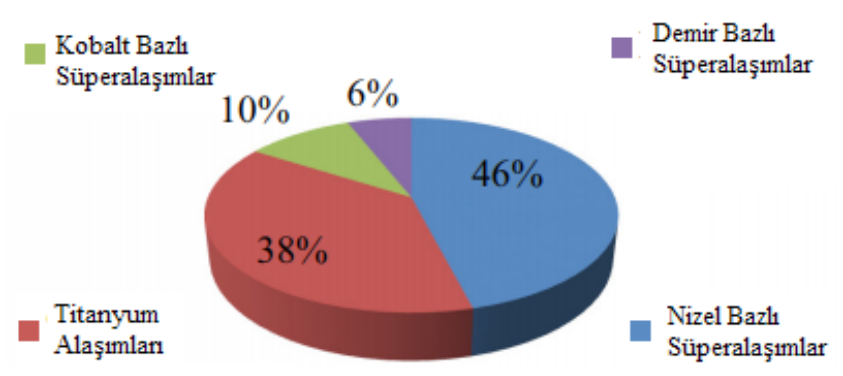

Şekil 1: Nikel alaşımlarının literatür araştırmalarında kullanılma sıklığına bir örnek[13].

Nikel alaşımlarının işlenebilirliği, talaşlı imalat sırasında özellikle malzemenin düşük 1sıl iletkenliği ve yüksek mekanik mukavemeti nedeniyle kesme bölgesinde oluşan yüksek 1sı ve yüksek kesme kuvvetlerinin oluşumu ile doğrudan ilgilidir [6-7,12-13]. Literatürde nikel alaşımlarının işlenebilirliğinin artırılması konusu, genellikle talaşlı imalat parametrelerinin ve koşullarının optimizasyonu yaklaşımıyla ele alınmış, farklı kesme parametreleri ile farklı karakteristiklere sahip soğutma/yağlama koşulları altında karşılaştırmalı olarak test edilmiş ve sonuçları rapor edilmiştir[3,6-7,10-11]. Yapılan çalışmalara göre nikel alaşımlarının işlenebilirliğinin artırılması amacıyla kullanılan soğutma/yağlama metodlarının birbirlerine göre avantaj ve dezavantajarı bulunmaktadır[13]. Genellikle nikel alaşımlarının işlenebilirliği karşısındaki en önemli problemlerden biri olan kesme bölgesinde yüksek sıcaklık oluşumunun önlenmesinin amaçlandı ğı çok sayıda karşılaştırmalı çalışma bulunmaktadır[9,14-16]. Ancak genellikle sıvı nitrojen (LN2) ve Karbondioksit gazı (CO2) tabanlı kriyojenik soğutma metodlarının yalnız başına kullanıldığı talaşlı imalat süreçlerinde, kriyojenik soğutmanın yüksek soğutma kapasitesi nedeniyle, deney malzemenin sertleşmesine neden olarak kesme kuvvetlerinin artmasına neden olduğu ifade edilmiştir[17]. Bazı çalışmalarda ise; kesme kuvvetlerinin 
kesme parametrelerine göre arttığ 1 yada azaldığı $\operatorname{arttığ1da~}$ rapor edilmiştir[16,18-19,26]. Yapılan bir çalışmada nikel bazlı bir süperalaşım olan Inconel 718 süper alaşımının, kriyojenik sıv1 nitrojen (LN2), Minimum miktarda yağlama (MQL) ve kuru işleme koşulları altında tornalanması sırasında işlenebilirlik performansı incelenmiştir. Bu çalışmada, farklı soğutma/yağlama koşullarının sabit ilerleme oranı ( $\mathrm{f}=0.075 \mathrm{~mm} / \mathrm{dev}$.) ve kesme derinliği $(\mathrm{d}=0.8 \mathrm{~mm}$.) parametreleri kullanılarak, farklı kesme hızı değerlerinde $(\mathrm{Vc}=60 \mathrm{ve}$ $120 \mathrm{~m} /$ dak.) tornalanması sirasında; kesme kuvvetlerinin değişkenlik gösterdiği, kriyojenik soğutma metodunun yüksek kesme hızlarında kesme kuvvetleri açısından azaltıcı etki gösterirken MQL metodunun kesme kuvvetlerini art1rıcı etkiye neden olduğu ifade edilmiştir. Şekil 2'de Inconel 718'in farklı soğutma/yağlama koşullarının, sabit ilerleme ve kesme derinliği ile tornalanmasının kesme kuvvetlerine etkisi ifade edilmiştir[16].

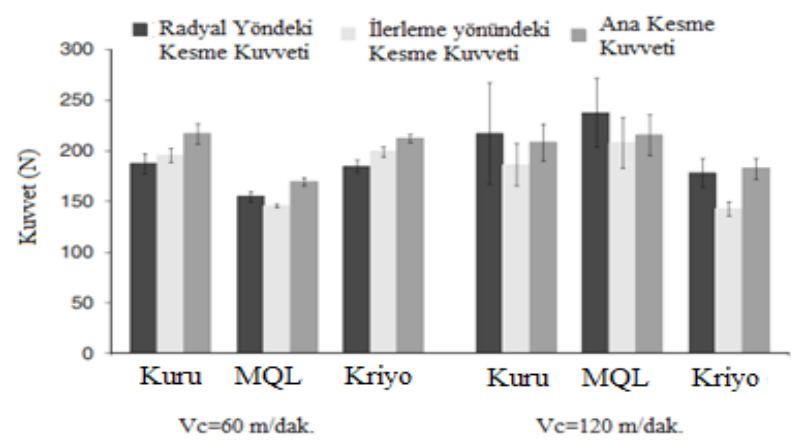

Şekil 2: Inconel 718'in farklı soğutma/yağlama koşulların altında, sabit ilerleme ( $\mathrm{f}=0.075 \mathrm{~mm} / \mathrm{dev}$.) ve kesme derinliği $(\mathrm{d}=0.8 \mathrm{~mm}$.) ile tornalanmasının kesme kuvvetlerine etkisi[16].

Aynı çalışmada; kesme kuvvetlerinin, kriyojenik sıvı iletim nozul sayısı arasında ilişki bulunduğu, nozul konumlarının, sayısının ve kullanılan kriyojenik sıvı miktarının, kesme kuvvetlerini artırdığ 1 ifade edilmiştir. Şekil 2, dikkatle incelendiğinde kriyojenik soğutmanın yüksek kesme hızlarında, MQL'in ise daha düşük kesme hızlarında kesme kuvvetlerini düşürme konusunda etkili olduğu görülmektedir[16]. Şekil 3'te nozul sayısının kesme kuvvetlerine etkisi görülmektedir[16].

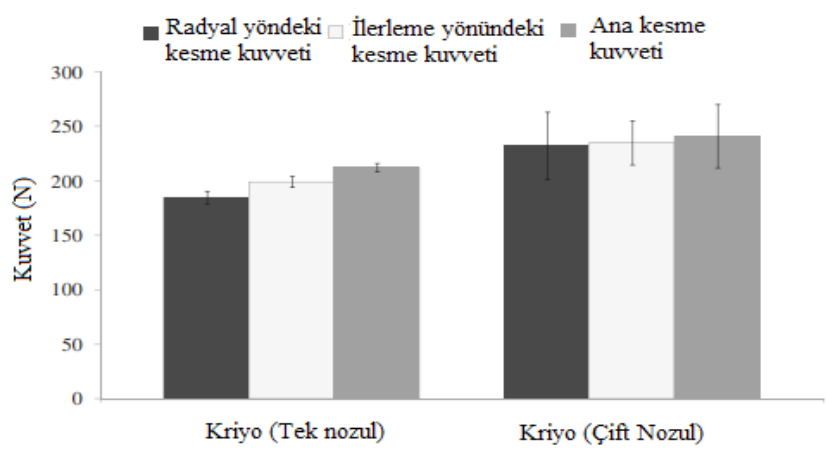

Şekil 3: Inconel 718'in Kriyojenik koşullar altında tornalanması sırasında nozul sayısının, kesme kuvvetlerine etkisi [16].

Yapılan bir diğer çalışmada ise Inconel 718'in tornalanması esnasında; yüksek basınçlı jet (HPJ), Kriyojenik sıvı nitrojen (LN2), Minimum miktarda yağlama (MQL) ve Nano sıvı takviyeli Minimum miktarda yağlama (nMQL) soğutma/yağlama metodları kullanılarak bazı çıktı parametreleri incelenmiştir. Bu parametrelerden biri kesme kuvvetidir. Bu çalışmaya göre, değişken işleme parametreleri olarak farklı kesme hızları, ilerleme oranları ve talaş açıları kullanılmıştır. Şekil 4'te Inconel 718'in farklı soğutma/yağlama metodları altında değişken kesme hızı, ilerleme oranı ve talaş açısı parametreleri kullanılarak tornalanması sırasında kesme kuvvetlerinin değişimi ifade edilmiştir. Şekil 4, dikkatlice incelenirse, farklı soğutma/yağlama metodlarının, değişken kesme parametrelerine bağlı olarak, kesme
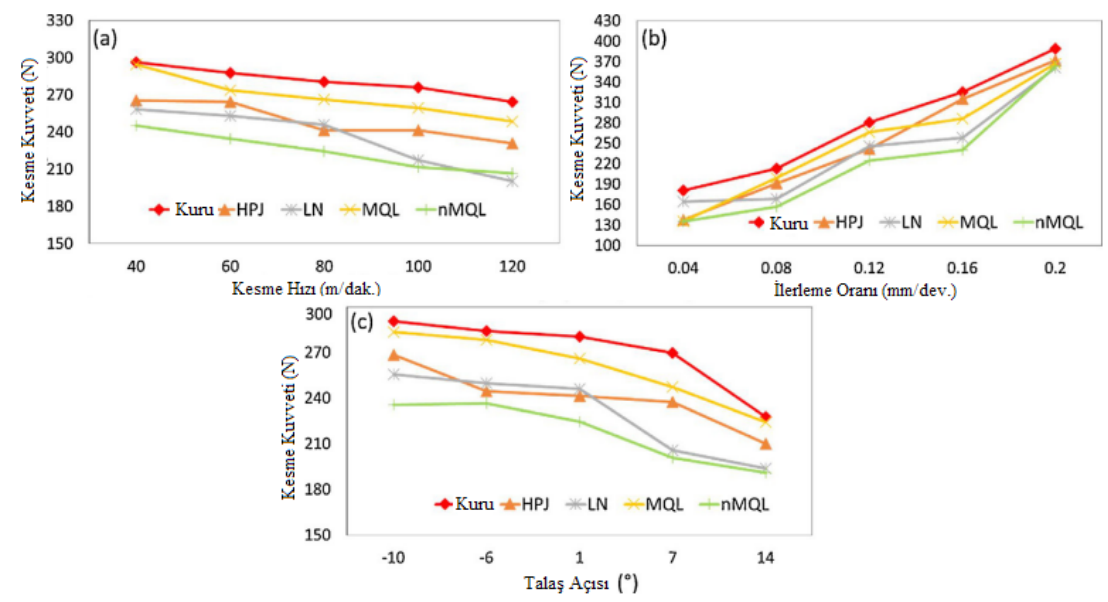

Şekil 4: Inconel 718'in Farklı soğutma/yağlama metodları altında değişken (a) Kesme hızı, (b) İlerleme oranı ve (c) Talaş açısı parametreleri kullanılarak tornalanması sırasında kesme kuvvetlerinin değişimi[20]. 
kuvvetlerini etkilediği görülmektedir. Şekil 4'te görüldüğü üzere, kriyojenik soğutma metodu; en yüksek kesme h1zında maksimum etkinlik göstermiş, İlerleme oranının değişimi kesme kuvvetleri üzerinde bir miktar etkili olmuş, maksimum talaş açısı arttıkça kriyojenik sıvı nitrojen (LN2) ve Nanosıvı takviyeli Minimum miktarda yağlama (nMQL) metodları birbirine yakın performans sergilemekle birlikte maksimum etkinlik sergilemiş̧ir [20].

Literatürde bulunan bir başka araştırmada, Inconel 718'in Kuru, Kriyojenik siv1 nitrojen (LN2) ve Konvansiyonel soğutma/yağlama koşulları altında, farklı özelliklerde kesici takımlar kullanılarak yapılan delik delme operayonunda birtakım parametreler incelenmiştir. Aralarında kesme kuvvetlerininde bulunduğu bu parametrelerin değişimleri incelenmiş ve bazı çıkarımlarda bulunulmuştur. Kesme kuvveti açısından ele alacak olursak delik delme işlemi sırasında oluşan kuvvetin en fazla olduğu durum TiAlN kaplamalı karbür matkabın, LN2 soğutma metodu ile birlikte kullanıldığı durum olduğu, şekil 5'te görülmekte$\operatorname{dir}[17]$.

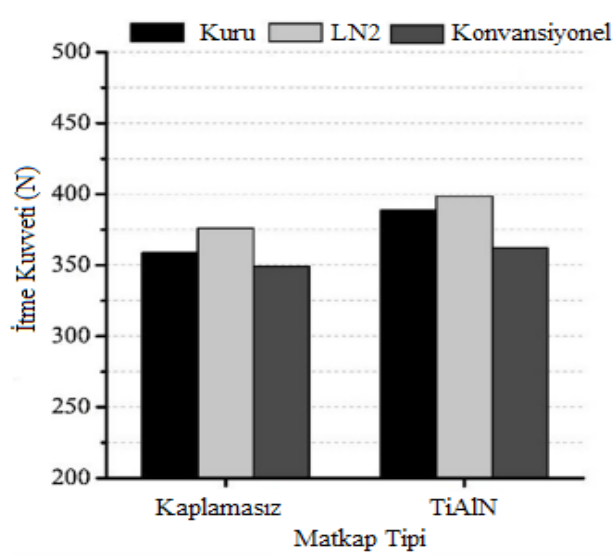

Şekil 5: Inconel 718'in Delik delme işleminde farklı soğutma/ yağlama koşulları altında, TiAlN kaplamalı ve kaplamasız karbür matkaplarla delinmesinin itme kuvvetine etkisi[17].

Literatürde yapılan bir başka çalışmada ise yine Inconel 718'in kuru ve Minimum miktarda yağlama (MQL) metodu ile farklı katkı maddeleri kullanılarak tornalanmasının; kesme kuvvetleri, takım aşınması, yüzey bütünlüğü parametreleri üzerinden karşılaştırması yapılmıştır. Yapılan karşılaştırmada, ilerleme oranı $(\mathrm{f}=0,1 \mathrm{~mm} / \mathrm{dev})$, talaş derinliği $(\mathrm{d}=0,5$ $\mathrm{mm}$.) ve değişken kesme hızları ( $\mathrm{Vc}=10-150-200-250-300$ $\mathrm{m} /$ dak) kullanılmış ve MQL metodu için biyolojik esaslı bitkisel yağ (LB2000), katı yağlayıcı partikülleri olarak (ağırlıça \%20) Grafit ve Molibden Sülfat (MoS2) ile desteklenmiştir. Elde edilen sonuçlara göre kesme kuvvetleri açısında MoS2 destekli biyo-yağ kullanılan MQL metodunun, kesme hızının düzeyine paralel olarak kesme kuvvetlerinde artış yada azalışa neden olduğu ancak bu durumun stabil olmadığı görülmüş, grafit katı partikül takviyeli MQL'in kesme hızı artışına paralel olarak $300 \mathrm{~m} /$ dak gibi yüksek bir kesme hızı düzeyinde en verimli metod olduğu ifade edilmiştir. Kuru işleme metodunun ise kesme kuvvetleri konusunda en verimsiz metod olduğu, şekil 6 incelendiğinde net olarak görülebilir. Şekil 6'da Inconel 718'in farklı soğutma/yağlama koşulları altında tornalanmasının kesme kuvvetlerine etkisi detaylı olarak görülebilmektedir[22].

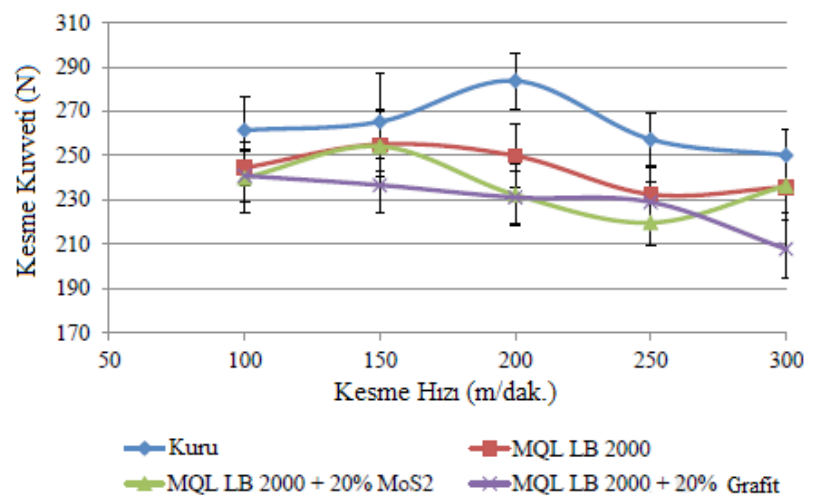

Şekil 6: Inconel 718'in Kuru ve Farklı MQL koşulları altında tornalanmasının kesme kuvvetlerine etkisi[22].

Inconel 718'in konvansiyonel sıv1, kriyojenik karbondioksit (CO2) gazı, Minimum miktarda yağlama (MQL) ve hibrid KriyoMQL (CO2+MQL) koşullar altında frezelenmesinin, kesme kuvvetleri ve takım aşınması üzerindeki etkilerini inceleyen bir diğer çalı̧̧mada ise kriyojenik soğutucu olarak karbondioksit gazı (CO2) kullanılmış ve elde edilen sonuçlar kesme kuvvetleri açısından Şekil 7'da ifade edilmiştir. Yapılan bu deneysel çalışmada; kesme hızı $(\mathrm{Vc}=60 \mathrm{~m} / \mathrm{dak}$.) ilerleme oranı $(\mathrm{f}=0,02 \mathrm{~mm} /$ diş $)$ ve talaş derinliği $(\mathrm{d}=0,2 \mathrm{~mm})$ olarak belirlenmiş ve takım aşınma kriterlerine göre kesme kuvvetleri üzerinden değerlendirme yapılmıştır. Aşınma kriterleri, $(\mathrm{Vb}=0-0,1-0,2 \mathrm{~mm}$.) olarak referans alınmıştır[25].

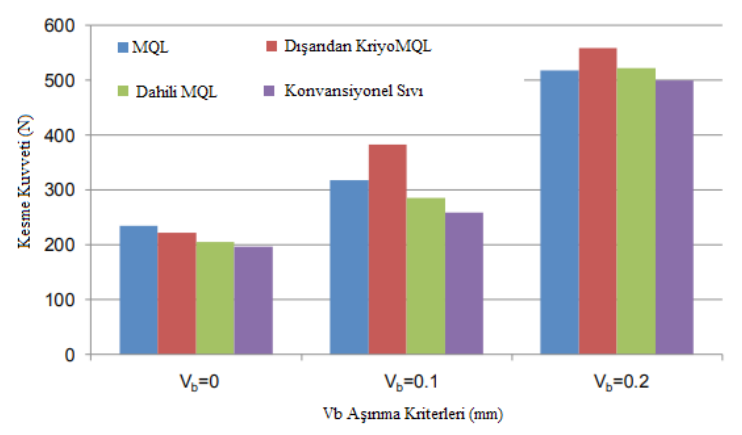

Şekil 7: Vc=60m/dak. Kesme hızında farklı aşınma kriterlerinde ve işleme koşullarında kesme kuvvetleri[25]. 
Şekil 7'de aşınma kriterleri referans alınarak farklı soğutma/yağlama koşulları altında oluşan kesme kuvvetleri incelendiğinde, takım aşınma durumunun kesme kuvvetleri üzerinde etkiye sahip olduğu açıkça görülmektedir. Yapılan çalışmaya göre, genel olarak takım üzerindeki aşınma arttıkça, kesme kuvvelerinin arttığı gözlenmiştir. Soğutma/yağlama metodları açısından bakılacak olursa, minimum takım aşınma miktarının olduğu durumda kesme kuvvetleri birbirine oldukça yakın olmakla birlikte tüketilen soğutma/yağlama sıvısı açısından dahili Kriyojenik Karbondioksit gazı (CO2) takviyeli minimum miktarda yağlama $(\mathrm{CO} 2+\mathrm{MQL})$ metodunun oldukça avantajlı olduğu görülmektedir[25].

Inconel $718^{\prime}$ in yüksek kesme hızlarında ve farklı soğutma/yağlama koşulları altında frezelenmesi sırasıda işlenebilirliğinin incelendiği bir başka çalışmada, $50 \mathrm{~mm} \mathrm{x}$
$50 \mathrm{~mm} \times 150 \mathrm{~mm}$ boyutlarında bir Inconel 718 süperalaşım bloğu, sabit kesme hızı (Vc=140m/dak.), ilerleme oranı $(\mathrm{f}=0,02 \mathrm{~mm} /$ diş$)$, Eksenel kesme derinliği, $(\mathrm{a}=10 \mathrm{~mm}$.) ve radyal kesme derinliği $(\mathrm{d}=1 \mathrm{~mm})$ işleme parametreleri ile Konvansiyonel kesme sıvıs1, Minimum miktarda yağlama (MQL), Siv1 nitrojen (LN2) ve KriyoMQL (LN2+MQL) soğutma/yağlama koşulları altında frezeleme işlemine tabii tutulmuş ve sonuçlar takım ömrü, kesme operasyonu için sarfedilen güç miktarı, Yüzey pürüzlülüğü değerleri üzerinden karşılaştırmalı olarak ele alınmıştır. Hibrid KriyoMQL (LN2+MQL) metodunun, tek başına MQL ve tek başına LN2 soğutma/yağlama koşullarına göre, incelenen tüm çıktı parametrelerinde en verimli metod olduğu ifade edilmiştir. Şekil 8: Inconel 718'in farklı soğutma/yağlama metodları altında yüksek kesme hızında frezelenmesinin aşınma miktarı,

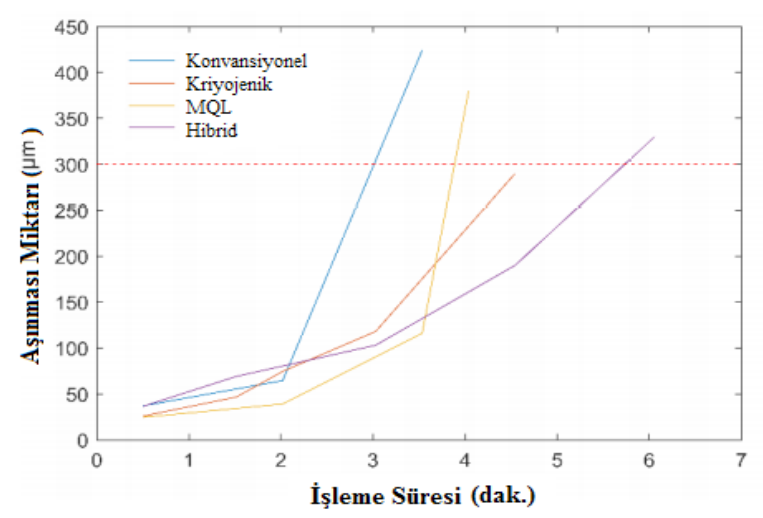

(a)

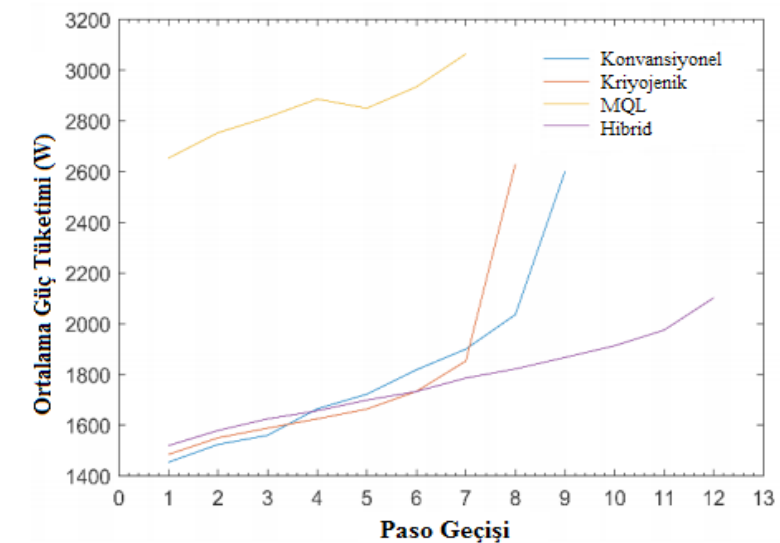

(b)

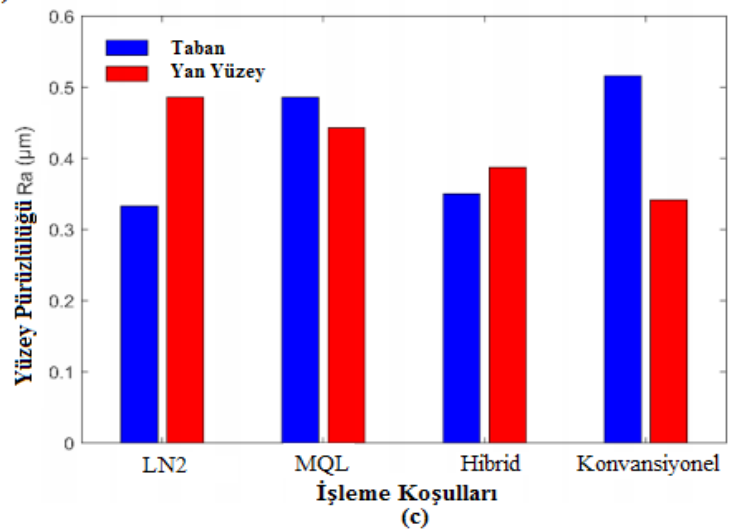

Şekil 8: Inconel 718'in Farklı soğutma/yağlama metodları altında yüksek kesme hızında frezelenmesinin (a) Aşınma miktarı, (b) Ortalama güç tüketimi ve (c) Yüzey pürüzlülüğü değerleri üzerinden karş1laştırılması [26].

Şekil 8'de görüldüğü üzere Kriyojenik sıvı nitrojen (LN2) ve Minimum miktarda yağlama (MQL) metodlarının oluşturduğu hibrit kriyoMQL (LN2+MQL) soğutma/yağlama metodu, LN2, MQL ve konvansiyonel metodların ayrı ayrı kullanıldığ̣ durumlara göre takım aşınmasını daha fazla azaltmış, bununla ilişkili olarak güç tüketimi ve yüzey pürüzlülüğü değerlerinide göreceli olarak azaltarak, verimlilik ve işlenebilirlik artışı sağlamıştır[26]. 


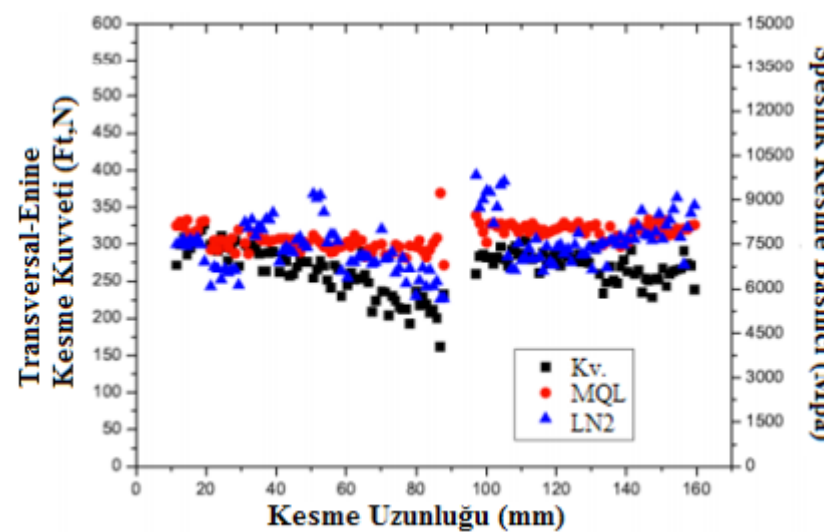

(a)

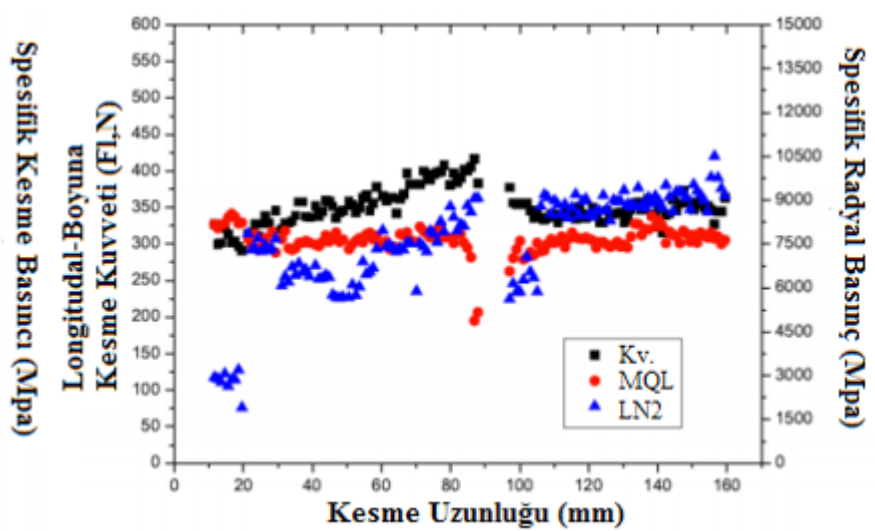

(b)

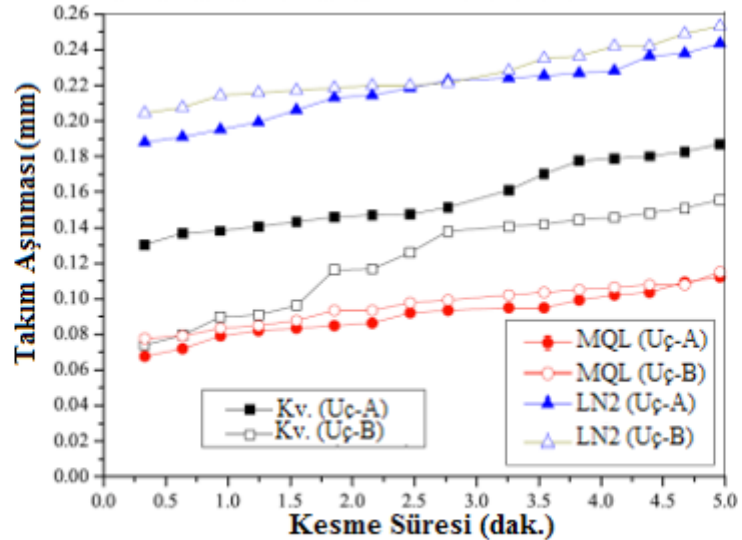

(c)

Şekil 9: Inconel 718'in Farklı soğutma/yağlama metodları altında, düşük hızda frezelenmesinin; (a) Enine Kesme Kuvveti (Ft), (b) Boyuna Kesme Kuvveti (Ft), ve (c) Yüzey pürüzlülüğü üzerinden karşılaştırılması[27].

ortalama güç tüketimi ve yüzey pürüzlülüğü değerleri üzerinden karşılaştırılması ifade edilmiştir [26].

Şekil 9'de gösterilen sonuçlara göre MQL metodu en az takım aşınması sergilemiş buna karşın, boyuna kesme kuvvetini (Fl) azaltmak açısından, frezeleme işleminin başlangıcında LN2 metodunun gerisinde kalmış, işlemin sonlarına doğru LN2 metoduna göre avantaj sağlamıştır. MQL metodu, kesme işlemi süresince, boyuna kesme kuvveti (Fl) açısından diğer metodlara göre daha stabil değerler sağlamış, buna karşın Enine kesme kuvveti (Ft) konusunda kesme işlemi süresince hemen hemen en yüksek kesme kuvveti değerleri sergilemiştir. Genel olarak Enine kesme kuvveti (Ft) açısından, konvansiyonel soğutma/yağlama metodu en iyi performansı sergilemiş ve boyuna kesme kuvvetini (Fl) açısından, LN2 ve MQL metodları oldukça yakın değerler ortaya koymuştur[27].

Inconel 718'in kuru ve Kriyojenik CO2 koşullarında yüksek hızda tornalanmasının; işlem kuvvetleri, yüzey pürüzlülüğü, mikro sertlik, spesifik kesme basıncı üzerindeki etkileri, karşılaştırmalı olarak incelendiği bir başka çalışmada çalışmada ise işleme parametreleri olarak, değişken kesme hizları ( $\mathrm{Vc}=80-85-100-115-130 \mathrm{~m} / \mathrm{dak})$ ve ilerleme oranları ( $\mathrm{f}=0,10-0,17-0,24-0,32-0,40 \mathrm{~mm} / \mathrm{dev}$.) kullanılmıştır. Elde edilen sonuçlar Kriyojenik CO2 koşullarında, düşük kesme hızlarında yapılan kesme operasyonunda ortaya çıkan kesme kuvvetlerinin, kriyojenik CO2'nin malzemenin sertleşmesine neden olmasından dolayı, kuru işlemeye nazaran daha yüksek olduğu, nispeten yüksek kesme hızlarında ise kesme kuvvetlerinin, iş malzemesinin sıcaklığının yükselmesinden dolayı azaldığı görülmüştür. Kriyojenik CO2 koşullarında işleme operasyonu sırasında kesme hızı artırıldıkça kesme kuvvetlerinin azalmasına paralel olarak takım aşınma miktarı azalmış ve bununla ilişkili olarakta yüzey pürüzlülüğü azalmıştır. Her iki soğutma/yağlama koşulunda'da kesme hızı ve ilerleme oranı paralel olarak artırıldığında yüzey pürüzlülüğ̈ünunde arttığ́1 görülmüştür[28]. Şekil 10'da Inconel 718'in farklı kesme hızlarında; kuru işleme koşullarında, Kriyojenik (CO2) koşullarında işleme sırasında oluşan kesme kuvvetleri ve yüzey pürüzlülügüü üzerinden karşılaştırılması detaylı olarak sunulmuştur[28]. 


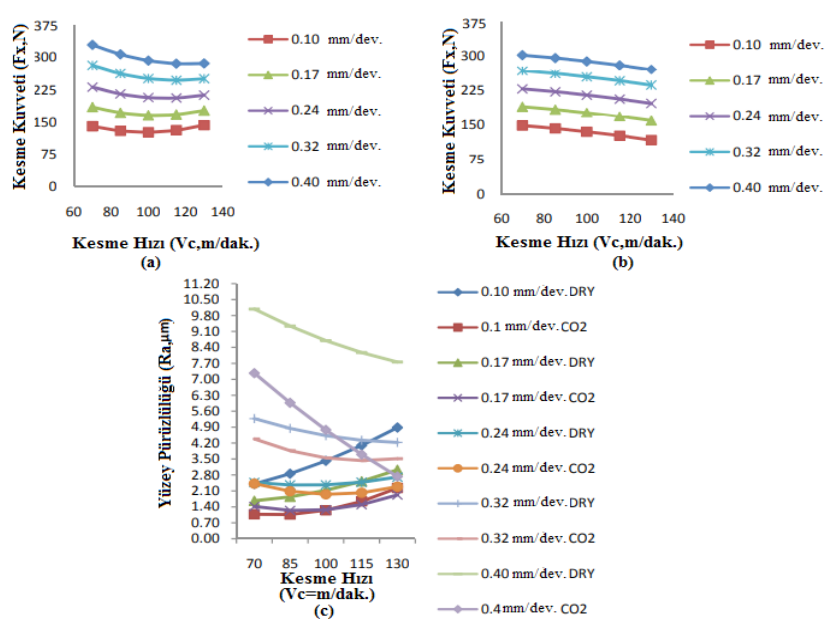

Şekil 10: Inconel 718'in farklı kesme hızlarında; (a) kuru koşullarında, (b) Kriyojenik koşullarda işleme sırasında oluşan kesme kuvvetleri ve (c) Yüzey pürüzlülüğü üzerinden karşılaştırılması[28].

Inconel 718'in Kuru, soğutulmuş basınçlı hava ve nanosıvı takviyeli minimum miktarda yağlama şartları altında tornalanması sırasında oluşan spesifik kesme kuvvetlerini incelemek amacıyla yapılan bir başka çalışmada değişken işleme parametreleri olarak farklı kesme hizları $(\mathrm{Vc}=60-70-80-90$ $100-110 \mathrm{~m} /$ dak.) ve ilerleme oranı ( $\mathrm{f}=0,1-0,2-0,3-0,4 \mathrm{~mm} /$ dev) olarak belirlenmiş ve talaş derinliği $(a=0,25 \mathrm{~mm})$ sabit tutulmuştur[29]. Şekil 11'de Inconel 718'in farklı kesme hızları ve ilerleme oranlarında; kuru, soğutulmuş basınlı hava (Vortex tüpü), nano yağlayıcı takviyeli MQL koşullarında işlenmesinde, tüketilen güç - malzeme kaldırma oranı ilişkisi görsel olarak sunulmuştur[29].

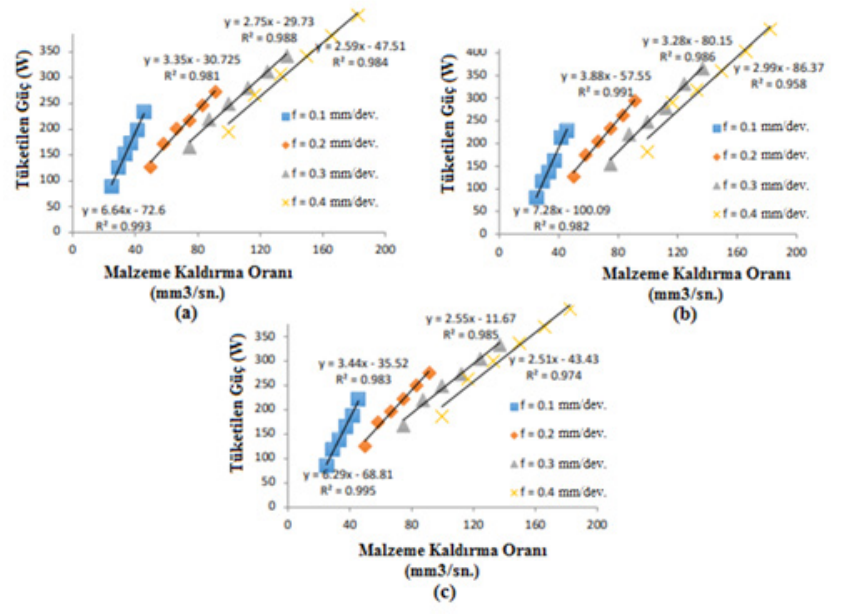

Şekil 11: Inconel 718'in farklı kesme hızları ve ilerleme oranlarında; (a) kuru, (b) Soğutulmuş Basınlı hava, (c) Nano yağlayıcı takviyeli MQL koşullarında işlenmesinde, Tüketilen Güç - Malzeme kaldırma oranı ilişkisi[29].
Şekil 11, detaylı olarak incelendiğinde; görsellerde her bir ilerleme oranı (f) değerine karşılık kesme hızlarını (Vc) temsilen 4 renkten 6'şar adet renkli nokta bulunmaktadır. Buna göre Nano yağlayıcı takviyeli Minimum miktarda yağlama metodunun (nMQL) uygulandığ 1 deneylerde, en yüksek verim elde edildiği görülmektedir. Deneylerde nMQL metodunu kuru işleme metodu takip ederken en düşük verim, basınçlandırılmış soğuk hava (Vortex tüpü) metodunun kullanıldığ deneylerde görülmüştür. Şekil 12'de Inconel 718'in farklı ilerleme oranlarında; kuru, soğutulmuş basınlı hava (Vorteks Tüpü), Nano yağlayıcı takviyeli minimum miktarda yağlama (nMQL) koşullarında işlenmesinde, spesifik kesme enerjisi - ilerleme oranı ilişkisi görümekte ve şekil 11'deki sonuçları desteklemekte$\operatorname{dir}[29]$.

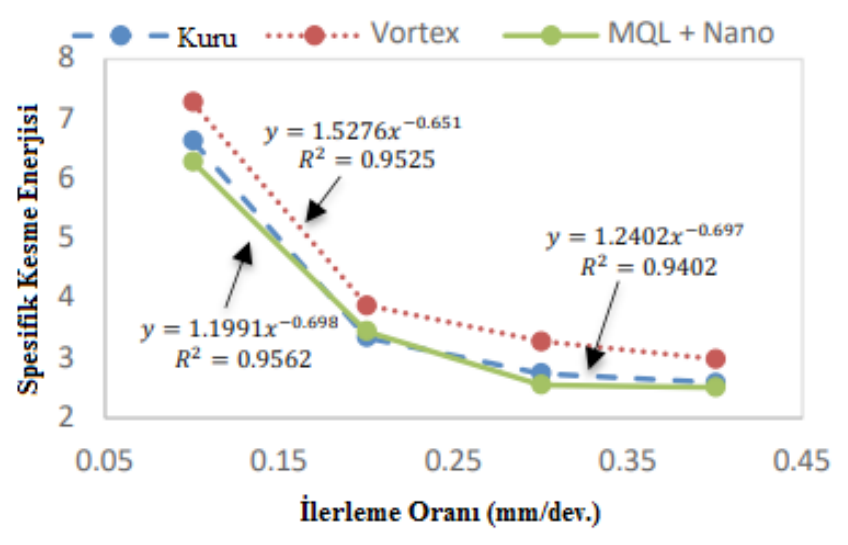

Şekil 12: Inconel 718'in farklı ilerleme oranlarında; kuru, Soğutulmuş Basınlı hava (Vorteks Tüpü), Nano yağlayıcı takviyeli MQL koşullarında işlenmesinde, Spesifik kesme enerjisi İlerleme oranı ilişkisi[29].

Yapılan bir başka çalışmada Inconel 718'in kuru, Konvansiyonel ve MQL soğutma/yağlama koşulları altında, işleme parametreleri olarak değişken kesme hızları $(\mathrm{Vc}=40-60-80-100-120 \mathrm{~m} / \mathrm{dak}$.$) , ilerleme oranları (\mathrm{f}=0,04$ $0,08-0,12-0,16-0,20 \mathrm{~mm} / \mathrm{dev})$ ve sabit talaş derinliği $(\mathrm{a}=0,5 \mathrm{~mm})$ kullanılarak işleme deneyleri gerçekleştirildiği bir başka çalışmada ise, çalışmaların sonuçları, kesme kuvvetleri, yüzey pürüzlülüğü ve talaş oluşumu üzerinden karşılaştırmalı olarak değerlendirilmiş ve sonuçlar şekil 13'de ifade edilmişsir[30]. 


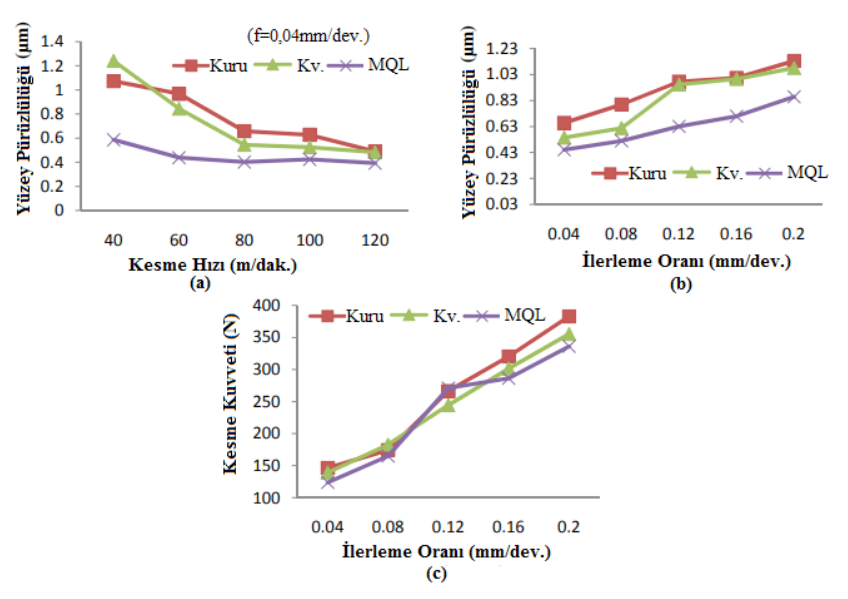

Şekil 13: Inconel 718'in kuru, Konvansiyonel ve MQL koşullarında tornalanması sırasında, (a) kesme hızı, (b) ilerleme oranı değişiminin yüzey püzülülügüüe etkisi, (c) Kesme kuvvetiİlerleme oranı ilişkisi[30].

Şekil 13'te sunulan sonuçlar incelendiğinde, en düşük kesme kuvvetlerinin, minimum miktarda yağlama (MQL) metodunun, en küçük ilerleme oranı parametresi olan ( $\mathrm{f}=0,04 \mathrm{~mm} / \mathrm{dev}$.) ilerleme oranı değeriyle birlikte kullanldığı deneyde elde edildiği ve yine aynı ilerleme değeri sabit tutularak, kesme hızları yükseldikçe yüzey pürüzlülüğünün azaldığı gözlenmiştir. Çalışmanın sonucu, minimum miktarda yağlama (MQL) metodunun, ( $\mathrm{f}=0,12 \mathrm{~mm} / \mathrm{dev}$ ) ilerleme oranında diğer metodların üzerinde bir kesme kuvveti oluşturmasına karşın, diğer ilerleme oranlarında en düşük kesme kuvvetlerinin oluşmasını sağladığı ve en düşük yüzey pürüzlülüğü değerlerini ortaya koyduğu belirgin olarak görülmektedir[30].

\section{SONUÇLAR VE DEĞERLENDİRME}

Nikel alaşımlarının talaşlı imalatı konusunda literatürde bulunan çalışmalar genellikle, Endüstrilerde sık kullanılması nedeniyle, Inconel 718 alaşımının farklı kesme şartları ve kesme parametreleri altında talaşlı imalat işlemine tabi tutulmasının, yüzey ve yüzeyaltı bütünlüğü özellikleri, kesme kuvvetleri, takım ömrü gibi çıktılar üzerinden karşılaştırılması üzerine yapılmıştır[12,16-18,20,22,26-30]. Konu ile ilgili genel bir literatür araştırması yapıldığında ve elde edilen sonuçlar karşılaştırıldığında; nikel alaşımlarının talaşlı imalatında kriyojenik sıvı nitrojen (LN2) ve kriyojenik karbondioksit gazı (CO2) kullanılarak yapılan soğutma uygulamalarının düşük kesme hızlarında, kesme sıcaklığının niseten düşük olduğu durumlarda, malzemeyi fazla soğutması nedeniyle kesme kuvvetleri ve takım aşınmasında artışa eden olabileceği, bu durumun ise kesme hızları ve ilerleme oranlarını nispeten daha yüksek seçerek belli oranda önlenebileceği gözlenmiştir. Minimum miktarda yağlama (MQL) türevlerinin kullanıldığı çalışmalar incelendiğinde orta düzey kesme hızlarında bu metodun yüzey pürüzlülügü ve kesme kuvvetleri konusunda verimli olabileceği ancak yüksek kesme hızlarında soğutma konusunda yetersiz kalarak, takım aşınması ve kuvvet artışıyla birlikte, takım aşınmasınıda artırdığı gözlenmiştir[17,20,25,26,28]. Genel olarak farklı soğutma/yağlama koşullarının, tek başına kullanılarak talaşlı imalat sırasında oluşan kesme kuvvetlerininin verimli ve sürdürülebilir bir şekilde azaltılabilmesi pek mümkün görünmemektedir. Son yıllarda sıkça araştırma konusu olan kriyojenik soğutma içeren hibrid soğutma/yağlama metodlarının, talaşlı imalat operasyonlarında kesme kuvvetlerinin azaltılması konusunda diğer metodlara nispeten daha verimli olduğu ifade edilmişsede yapılan çalışma sayısı henüz kısitlıdır[6,14,17,20,25,26,29] . Kriyojeik metodların ve Minimum miktarda yağlama metodu türevlerinin münferit olarak yetersiz kaldığı durumlarda, genel olarak nikel alaşımlarının işlenmesinde başta hibrit soğutma/yağlama metodlarının, kesme hızının yüksek olduğu durumlarda oldukça etkili olabileceği görülmektedir[16,20,22,26,27,30]. Elde edilen sonuçlara göre, nikel alaşımlarının talaşlı imalat operasyonlarında, düşük kesme hızlarının tercih edilmesi durumunda, kriyojenik metodların soğutma kabiliyetlerinin sebep olduğu malzeme sertleşmesi problemlerine bağlı takım aşınması, kesme kuvvetlerinin artışı ve yüzey pürüzlülüğünün artması problemleri; Minimum miktarda yağlama metodu ve türevlerinin, yüksek hızlarda kullanılmasında'da görülmektedir. Soğutma/ yağlama metodlarının karakteristiklerinden kaynaklanan olumsuz etkileri azaltmak gerekmektedir. Kriyonenik metodların yüksek soğutma kapasitesinin yeterli düzeyde yağlama kapasitesiyle desteklenmesi için, Minimum miktarda yağlama (MQL) metodu ve türevlerinin iyi düzeydeki yağlama özelliklikleri kullanılabilir. Böylece Kriyojenik ve Minimum miktarda yağlama (MQL) metodlarının dezavantajları, münferit metodlara göre azalacak ve nikel alaşımların talaşlı imalatında verimlilik ve işlenebilirlik artışı sağlanabilecektir. Bütün bunlarla birlikte sadece soğutma/yağlama metodları üzerinden değerlendirmelerde bulunmak sağlıklı bir yaklaşım değildir. Dolayısıyla kullanılacak soğutma/yağlama metodları yanısıra, kesme parametreleri ve talaşl imalat metodunun birlikte ve en uygun şekilde seçilmesi gerekmektedir. Nikel alaşımlarının talaşlı imalatında, kesme kuvvetlerinin incelenmesi konusundaki yaklaşımlarının çeşitlendirilmesi, hibrid soğutma/yağlama metodlarının geliştirilmesi ve kesme kuvvetlerinin azaltılması için gereken soğutma/yağlama, malzeme tipi, parametre grubu, imalat metodu kombinasyonlar1nın daha fazla netleştirilebilmesi için, bu alanda daha fazla sayıda araştırma yapılması gerekmektedir. 


\section{KAYNAKLAR}

[1] Aluminum Association. (1984). Aluminum: properties and physical metallurgy. ASM international..

[2] Lin, J., Balint, D., \& Pietrzyk, M. (Eds.). (2012). Microstructure evolution in metal forming processes. Elsevier.

[3] ALTIN, A. (2010). Inconel 718 Süper Alaşımının Sementit Karbür Kesici Takımlar ile İşlenmesinde, Kesici Takım Kimyasal Özelliklerinin Takım Performansına Etkileri. Yüzüncü Y1l Üniversitesi Fen Bilimleri Enstitüsü Dergisi; Cilt: 15 Say1: 2; 89-94.

[4] Ezugwu, E. O. (2007). Improvements in the machining of aero-engine alloys using self-propelled rotary tooling technique. Journal of Materials Processing Technology, 185(1-3), 60-71.

[5] Ulutan, D., \& Ozel, T. (2011). Machining induced surface integrity in titanium and nickel alloys: A review. International Journal of Machine Tools and Manufacture, 51(3), 250-280..

[6] Thellaputta, G. R., Chandra, P. S., \& Rao, C. S. P. (2017). Machinability of nickel based superalloys: a review. Materials Today: Proceedings, 4(2), 3712-3721.

[7] Ezugwu, E. O., Wang, Z. M., \& Machado, A. R. (1999). The machinability of nickel-based alloys: a review. Journal of Materials Processing Technology, 86(1-3), 1-16.

[8] Çakır,M.C.(2000);” Modern Talaşlı İmalatın Esasları”, Dora Basım Yayın,İstanbul,Türkiye s.12-275.

[9] Iturbe, A., Hormaetxe, E., Garay, A., \& Arrazola, P. J. (2016). Surface integrity analysis when machining inconel 718 with conventional and cryogenic cooling. Procedia CIRP, 45, 67-70.

[10] Balan, A. S. S., Vijayaraghavan, L., Krishnamurthy, R., Kuppan, P., \& Oyyaravelu, R. (2016). An experimental assessment on the performance of different lubrication techniques in grinding of Inconel 751. Journal of advanced research, 7(5), 709-718.

[11] Sinha, M. K., Madarkar, R., Ghosh, S., \& Rao, P. V. (2017). Application of eco-friendly nanofluids during grinding of Inconel 718 through small quantity lubrication. Journal of cleaner production, 141, 1359-1375.

[12] Pleta, A., \& Mears, L. (2016). Cutting Force Investigation of Trochoidal Milling in Nickel-Based Superalloy. Procedia Manufacturing, 5, 1348-1356.

[13] Czan, A., Sajgalik, M., Holubjak, J., Zauskova, L., Czanova, T., \& Martikan, P. (2017). Identification of Temperatures in Cutting Zone when Dry Machining of Nickel Alloy Inconel 718. Procedia Manufacturing, 14, 66-75.

[14] Uçak, N., \& Çiçek, A. (2017, September). Talaşlı İmalat Süreçlerinde Kriyojenik Soğutma Uygulamaları Üzerine Bir Araştırma. In 5th International Symposium on Innovative Technologies in Engineering and Science 29-30 September 2017 (ISITES2017 Baku-Azerbaijan).

[15] He, Z. H., Zhang, X. M., \& Ding, H. (2016). Comparison of residual stresses in cryogenic and dry machining of inconel 718. Procedia Cirp, 46, 19-22.

[16] Kaynak, Y. (2014). Evaluation of machining performance in cryogenic machining of Inconel 718 and comparison with dry and MQL machining. The International Journal of Advanced Manufacturing Technology, 72(5-8), 919-933.

[17] Uçak, N., \& Çiçek, A. (2018). The effects of cutting conditions on cutting temperature and hole quality in drilling of Inconel 718 using solid carbide drills. Journal of Manufacturing Processes, 31, 662-673.

[18] Xia, T., Kaynak, Y., Arvin, C., \& Jawahir, I. S. (2016). Cryogenic cooling-induced process performance and surface integrity in drilling CFRP composite material. The International Journal of Advanced Manufacturing Technology, 82(1-4), 605-616.

[19] Aramcharoen, A., \& Chuan, S. K. (2014). An experimental investigation on cryogenic milling of Inconel 718 and its sustainability assessment. Procedia Cirp, 14, 529-534.

[20] Behera, B. C., Alemayehu, H., Ghosh, S., \& Rao, P. V. (2017). A comparative study of recent lubri-coolant strategies for turning of Ni-based superalloy. Journal of Manufacturing Processes, 30, 541-552.

[21] Akkurt, M.(1992).Talaş Kaldırma Yöntemleri Ve Takım Tezgahları. Birsen Yayınevi, İstanbul, Türkiye, s.5-66.

[22] Marques, A., Suarez, M. P., Sales, W. F., \& Machado, Á. R. (2019). Turning of Inconel 718 with whisker-reinforced ceramic tools applying vegetable-based cutting fluid mixed with solid lubricants by MQL. Journal of Materials Processing Technology, 266, 530-543.

[23] Weber, J. H., \& Banerjee, M. K. (2016). Nickel and nickel alloys: an overview.

[24] Kale, A., \& Khanna, N. (2017). A Review on Cryogenic Machining of Super alloys Used in Aerospace Industry. Procedia Manufacturing, 7, 191-197.

[25] Pereira, O., Urbikain, G., Rodríguez, A., Fernández-Valdivielso, A., Calleja, A., Ayesta, I., \& de Lacalle, L. L. (2017). Internal cryolubrication approach for Inconel 718 milling. Procedia Manufacturing, 13, 89-93.

[26] Shokrani, A., Dhokia, V., \& Newman, S. T. (2017). Hybrid cooling and lubricating technology for CNC milling of Inconel 718 nickel alloy. Procedia Manufacturing, 11, 625-632.

[27] de Paula Oliveira, G., Fonseca, M. C., \& Araujo, A. C. (2018). Residual stresses and cutting forces in cryogenic milling of Inconel 718. Procedia CIRP, 77, 211-214.

[28] Patil, N. G., Asem, A., Pawade, R. S., Thakur, D. G., \& Brahmankar, P. K. (2014). Comparative study of high speed machining of Inconel 718 in dry condition and by using compressed cold carbon dioxide gas as coolant. Procedia CIRP, 24, 86-91.

[29] Ali, M. A. M., Azmi, A. I., \& Khalil, A. N. M. (2018). Specific cutting energy of Inconel 718 under dry, chilled-air and minimal quantity nanolubricants. Procedia CIRP, 77, 429-432.

[30] Behera, B. C., Chetan, S. G., \& Rao, P. V. (2014, December). Effects on forces and surface roughness during machining Inconel 718 alloy using minimum quantity lubrication. In Fifth International and 26th All India Manufacturing Technology, Design and Research Conference (AIMTDR), Assam, India, Dec (pp. 12-14). 